\title{
LONG-DISTANCE TRUCK DRIVERS COPING STRATEGIES AND HARDINESS: SELF-ASSESSMENT PROCEDURE AND IMPLICIT ASSOCIATION TEST
}

\author{
Irina Plotka \\ Baltic International Academy, Latvia \\ Dmitry Igonin \\ Baltic International Academy, Latvia \\ Jelena Shaplavska \\ Baltic International Academy, Latvia \\ Daiga Kruzite \\ Baltic International Academy, Latvia \\ Nina Blumenau \\ Baltic International Academy, Latvia
}

\begin{abstract}
The activity efficiency of long-distance truck drivers is determined not only by professional knowledge and skills, but also the psychological features, such as hardiness and coping strategies to cope with stress. The relationship between coping strategies and hardiness measured with implicit methods has not been studied enough. The research aim is to study the relationship of hardiness measured by the Implicit Association Test (IAT) and self-assessment procedures with coping strategies among long-distance truck drivers. Research questions focused on the study of this relationship. Participants: 40 males, long-distance truck drivers, $M=29.6, S D=6.9$ years. Implicit method: Four experimental procedures of the IAT on the basis of two-categories were developed (IAT1 - Commitment, IAT2 - Control, IAT3 - Challenge, IAT4 - Hardiness). Explicit methods: „Dispositional Resilience Scale, DRS-15” (Bartone), Strategic Approach to the Coping Scale (Hobfoll). Positive and negative implicit effects for assessments of Hardiness, Control and Challenge were revealed. The greatest number of negative effects found in Challenge. The regression equation for the dependent variable Hardiness (implicit) contains predictors Control and Commitment, measured by the IAT. There is a difference in the relationship between coping strategies and implicitly and explicitly measured hardiness and its components.
\end{abstract}

Keywords: hardiness, strategies of coping behavior, explicit and implicit measures, implicit association test, long-distance truck drivers. 
Irina Plotka, Dmitry Igonin, Jelena Shaplavska, Daiga Kruzite, Nina Blumenau. LongDistance Truck Drivers Coping Strategies and Hardiness: Self-Assessment Procedure and Implicit Association Test

\section{Introduction}

Efficacy of drivers' activities is determined not only by professionally important knowledge, skills and abilities, but also by such an important characteristic as hardiness. Professional activities of long-distance truck drivers are associated with the constant risk and overcoming stress. Hardiness acts as a personal resource, increases the level of adaptive capacity and also affects the choice of efficient coping strategies in difficult life situations

Various researchers reveal different facets of a complex personality construct of hardiness. Hardiness is regarded as a pattern of attitudes, skills, and abilities which constitutes courage (Maddi, 2013), the ability not to lose health and self-possession under pressure of stressful situations (Bartone, Roland, Picano, \& Williams, 2008), as a way for the formation of psychological stability (Bartone, 2006, Bonanno, 2004, Maddi, 2005). Hardiness includes three main components: commitment, control, and challenge (Maddi, 2013). Commitment, as a component of hardiness, is an important characteristic of the personality, which is formed in the course of person's interaction with the environment, motivates a person to self-realization, leadership, healthy way of thinking and behavior. Control, as a component of hardiness, is expressed in ability to control the activities and ongoing events; it manifests itself in the active search for ways to influence on stress factors, as opposed to helplessness and passivity. The presence of this ability motivates a person to transform all the stress from potential disasters into the possibilities of personal growth. It is the aspiration for action, for fight, that allows you to influence on outcome of ongoing events, despite the fact that this influence might be not absolute, and success is not guaranteed. Challenge determines the openness and receptivity of a person to changes, which happening in his/her life, which are seen as opportunities (as opposed to fear of changes). If a person is able to perceive life situations as a challenge, he or she achieves a sense of satisfaction, using stress as an opportunity for development. Such people believe that it is possible to learn on mistakes as well as on the achievements (Maddi, 2013, Shaplavska \& Plotka, 2014).

In Latvia for several years the studies of hardiness using self-assessment procedures on samples of students, medical workers and rescue workers have been conducted. The studies showed the association between hardiness with a variety of psychological variables: coping strategies, tolerance for ambiguity, achievement motivation and life-meaning orientations. It was found that with the increase in hardiness the participants demonstrate active prosocial coping, using such strategies as seeking social support, social joining and assertive action. With the decrease of hardiness - passive strategies: avoidance and cautious action. Also, they found negative correlation of hardiness and its individual components with coping strategies: aggressive actions (Shaplavska \& Plotka, 2011; Shaplavska \& 
Plotka, 2012). Research results of numerous studies show that the hardiness is associated with successful coping in stressful situations and helps to preserve the physical and mental health (e.g. Contrada, 1989; Kobasa, Maddi, \& Kahn, 1982; Wiebe, 1991; Bartone, 2000; Britt, Adler, \& Bartone, 2001; Kelly, Matthews, \& Bartone, 2005; Grote, Weichbrodt, Günter, Zala-Mezö, \& Künzle, 2009; Bartone, Kelly, \& Matthews, 2013; Delahaija, Gaillard, \& van Damb, 2010; Sandvik, Bartone, Hystad, Phillips, Thayer, \& Johnsen, 2013) and others.

According to modern research, both the attitudes towards driving and the personal factors are important predictors of risky driving (Taubman-Ben-Ari \& Yehiel, 2012; Ucho, Terwase, \& Ucho, 2016; Fernandes \& Hatfield, 2006; Stephens, 2011; etc.).

The literature devoted to the study of attitudes towards driving and driver behavior, analyzes personality characteristics such as aggression, anxiety, extraversion, neuroticism, impulsiveness, sensation seeking, locus of control, and others, as well as attitudes and beliefs. As the most important traits that affect driving, the majority of scientists allocate: aggressiveness (Silberman, 2014; Oltedal \& Rundmo, 2006; Ulleberg \& Rundmo, 2003), impulsiveness and sensation seeking (Amirfakhraei, Taghinejad, \& Sadeghifar, 2013; Dahlen, Martin, Ragan, \& Kuhlman, 2005), extroversion, (Lajunen, 2001; Benfield, Szlemko, \& Bell, 2007; Clarke \& Robertson, 2005; Renner \& Anderle, 2000), neuroticism (Jovanovic, Lipovac, Stanojevic, \& Stanojevic, 2011; Oltedal \& Rundmo, 2006), depression (Hubicka, Kallmen, Hiltunen, \& Bergman, 2010), anxiety (Scott-Parker, Watson, King, \& Hyde, 2013) and some others. According to N. Sumer (2003), the severity of this personality characteristic is directly related to the frequency of involvement in traffic accidents.

A number of studies demonstrate the importance of examining the relationship between personality traits and attitudes of drivers (Yagil, 2001; Fernandes is et. al., 2006; Ulleberg \& Rundmo, 2002; Scott -Parker et. al., 2012).

As the researchers note, the absence of a direct effect of personality traits on risky behavior behind the wheel shows that personality traits have an indirect impact on behavior through their influence on attitudes. That is, the personality traits primarily affect the worldview determinants (attitudes) which in turn cause the intentions and future behavior of drivers (Ulleberg \& Rundmo, 2002). The analysis of the researches has shown the lack of studies using a construct such as the hardiness among the drivers. It was found, that this construct is researched mainly by explicit measurements. But there is still a shortage of researches of hardiness using implicit measures. Implicit measurements are defined as unconscious, automatic and indirect, and explicit measurements are defined as conscious, controlled and direct (Petty, Fazio, \& Brinol, 2009).

There are few papers on the study of hardiness with the Implicit Association Test (IAT) on samples of the participants whose professions are related to the risk 
(militaries, security guards, athletes) (Plotka, Shaplavska, Blumenau, Igonin, \& Kunavin, 2013; Shaplavska \& Plotka, 2014; Plotka, Shaplavska, Blumenau, \& Gajevska, 2015).

The research aim is to study the relationship of hardiness measured by the IAT and self-assessment procedures with coping strategies among long-distance truck drivers.

\section{Research questions:}

1. Are there differences between effects of implicit preferences for hardiness and its components, measured with IAT?

2. Are there differences between effects of explicit measured hardiness and its components?

3. How are implicitly measured preferences of hardiness and its components related to each other?

4. What is the contribution to implicitly estimated hardiness of its implicitly estimated components: commitment, control, challenge?

5. How are explicitly measured hardiness and its components related to each other?

6. How are explicitly and implicitly measured hardiness and its components related to each other?

7. How are implicitly and explicitly measured hardiness and its components related to coping strategies?

\section{Method}

Participants - 40 males living in Latvia, whose profession is long-distance truck drivers, aged $21-50$ years $(M=28.6, S D=6.9$ years, $M d n=27$ years $)$ work experience $1-21$ years, $(M=6.9, S D=4.8$ years, $M d n=6$ years $)$.

\section{Explicit measures}

„Dispositional Resilience Scale, DRS-15” (Bartone, Eid, Hystad, Johnsen, \& Laberg, 2008). To measure hardiness (Hardiness - Resilience), the research used the „Dispositional Resilience Scale (DRS-15)” by P. Bartone, which includes five characteristics of each hardiness component: commitment, control and challenge (Bartone et. al., 2008). The subscale of commitment determines how active the person is committed to life (as opposed to noncommitment) allows a person to feel important and valuable enough to be fully included in the decision of life tasks, despite the presence of stressful situations. The control determines the extent to which a person can influence on what is happening (as opposed to a sense of powerlessness). The challenge defines openness and sensitivity to changes in your life that are seen as opportunities for personal growth (as opposed to fear of changes). Overall hardiness (Hardiness - 
Resilience) is calculated as the sum of all three subscales of the questionnaire. Cronbah's alfa was not sufficiently high: $\alpha=.700$.

«Strategic Approach to the Coping Scale» (SACS) (Situational Form) by Hobfoll (1998). The questionnaire contains 9 models (scales) of coping behavior: assertive actions (active strategy); avoidance (passive strategy); seeking social support (prosocial strategy); cautious actions (passive strategy); social joining (prosocial strategy); instinctive actions (direct strategy); aggressive actions (antisocial strategy); antisocial actions (antisocial strategy); indirect actions (indirect strategy).

"Assertive actions" is the ability to be independent from external influences and evaluations of others, confidence in one's actions, honesty, integrity, selfesteem and respect for others.

"Avoidance" is mental aspirations and behavioural efforts aimed at avoiding the problem rather than to achieve success.

"Seeking social support" is reflected in an attempt to rely on others in getting emotional and real support, advice.

"Cautious actions" are defined both as a sign of weakness, and the need to avoid being tactless, and demonstrates a desire to understand others and to act so that the interactive group has supported and would not move away.

"Social joining" are the action in accordance with the group.

"Instinctive actions" are actions without sufficient conscious control, under the influence of external circumstances or because of emotional distress.

"Aggressive actions" occur in a critical attitude to the environment, involve direct „storm" of problems and are aimed at gaining control over the situation, rather than harm.

"Antisocial actions" are actions performed in order to hurt someone or express in indifference, obtaining benefits through the use of ,weak points" of other people to take a better position.

"Indirect (manipulative) actions" meant to hide one's true intentions.

Cronbah's alfa was not sufficiently high: $\alpha=.748$.

\section{Implicit measures:}

Modified versions of Two-Category Implicit Association Tests (TC-IAT): IAT1 (Commitment), IAT2 (Control), IAT3 (Challenge), IAT4 (Hardiness) developed on the basis of IAT (Greenwald, McGhee, \& Schwartz, 1998). For each procedure the appropriate categories and attributes were identified. The target attributes of IATs - the words of Schlosberg Scale (Schlosberg, 1952) with a strong affective meaning (positive or negative) were used. "Unpleasant" attributes: anger, disgust, contempt, evil, hatred. "Pleasant" attributes: peace, luck, love, joy, happiness. For correct selection of categories for measuring hardiness and its components, the authors relied on the theoretical approaches of "DRS-15" (Barton, 1998) was taken into consideration. For each IAT the 
Irina Plotka, Dmitry Igonin, Jelena Shaplavska, Daiga Kruzite, Nina Blumenau. LongDistance Truck Drivers Coping Strategies and Hardiness: Self-Assessment Procedure and Implicit Association Test

appropriate target categories have been identified. As target categories the authors used verbal stimuli representing a pattern of behavioral characteristics, determined by personality traits, its intentional and motivational characteristics, semantically associated with hardiness and its components. Target categories for each of the four IAT - „A Category” and their opposites „B Category” are shown in Table 1. These verbal stimuli prime appropriate cognitive-behavioral structures. For example, a person „directly” evaluates not the commitment, but the words - behavioral markers that correspond to his/her behavior, intentions and motivation. These words are associated with items of the DRS-15 questionnaire by Bartone. The IAT diagram is shown in Table 2.

As a result of IAT the $D$-scores (effect size) for implicitly measured variable "A - B implicit associations" were calculated (Rudman, 2011):

$$
D=\frac{1}{2}\left(\frac{M_{6}-M_{3}}{S D_{36}}+\frac{M_{7}-M_{4}}{S D_{47}}\right),
$$

where $M_{i}$ is the mean of reaction time (RT) in block " $i$ ", $S D_{i k}$ - is combined standard deviation for blocks " $i$ " and " $k$ ". 2011).

All trials with $R T<300 \mathrm{~ms}$ and $R T>10000 \mathrm{~ms}$ were deleted (Rudman,

The $D$-statistic is an effect size, based on each person's variance in response latencies. If $|D| \leq 0.15$ - no effect, if $0.15<|D| \leq 0.35$ - $\mathrm{p}$, if $0.35<|D|<0.60$ - medium effect size, if $|D| \geq 0.60$ - large effect size.

The positive values of $D$ show the preference of $\mathrm{A}$, the negative values preference of B (see Table 1).

Table 1 Target categories in four the IATs - two sets of words of „A Categories” and their opposites „B Categories” for each IAT

\begin{tabular}{cll}
\hline IAT & \multicolumn{1}{c}{ A Categories } & \multicolumn{1}{c}{ B Categories } \\
\hline $\begin{array}{c}\text { IAT1 - } \\
\text { Commitment }\end{array}$ & $\begin{array}{l}\text { Commitment, Consciousness, } \\
\text { Inclusion, } \\
\text { Life richness, Interest }\end{array}$ & $\begin{array}{l}\text { Isolation, Detachment, Meaningless Life } \\
\text { monotony, Boredom }\end{array}$ \\
\hline IAT2 - & $\begin{array}{l}\text { To act, To overcome, To } \\
\text { manage, To influence, To } \\
\text { determine }\end{array}$ & $\begin{array}{l}\text { To wait, To concede, To succumb, To go } \\
\text { with the flow, To depend on } \\
\text { circumstances }\end{array}$ \\
\hline IAT3 - & $\begin{array}{l}\text { Dynamism, Changes, Risk, } \\
\text { Challenge }\end{array}$ & $\begin{array}{l}\text { Stability, Consistency, Trustworthiness, } \\
\text { Safety, Stereotypeness }\end{array}$ \\
\hline IAT4 - & $\begin{array}{l}\text { Consciousness, Overcoming, } \\
\text { Hardiness }\end{array}$ & $\begin{array}{l}\text { Persistence, Energy, Risk } \\
\text { Senssness, Lack of initiative, }, \\
\text { Passivity, Avoiding the fight, Security }\end{array}$ \\
\hline
\end{tabular}


Table 2 Procedures of IAT1 - Commitment, IAT2 - Control, IAT3 - Challenge, IAT4 Hardiness

\begin{tabular}{lllll}
\hline Block & Trials & Function & Left-key response ,Q" & Right-key response ,P” \\
\hline 1 & 50 & Practice & B Categories & A Categories \\
\hline 2 & 26 & Practice & Unpleasant words & Pleasant words \\
\hline 3 & 50 & Test & $\begin{array}{l}\text { Unpleasant words }+ \\
\text { B Categories }\end{array}$ & $\begin{array}{l}\text { Pleasant words }+ \\
\text { A Categories }\end{array}$ \\
\hline 4 & 50 & Test & $\begin{array}{l}\text { Unpleasant words }+ \\
\text { B Categories }\end{array}$ & $\begin{array}{l}\text { Pleasant words }+ \\
\text { A Categories }\end{array}$ \\
\hline 5 & 50 & Practice & A Categories & B Categories \\
\hline 6 & 50 & Test & $\begin{array}{l}\text { Unpleasant words }+ \\
\text { A Categories }\end{array}$ & $\begin{array}{l}\text { Pleasant words }+ \\
\text { B Categories }\end{array}$ \\
\hline 7 & 50 & Test & $\begin{array}{l}\text { Unpleasant words }+ \\
\text { A Categories }\end{array}$ & $\begin{array}{l}\text { Pleasant words }+ \\
\text { B Categories }\end{array}$ \\
\hline
\end{tabular}

Apparatus. Certified licensed software E-Prime 2.0 Professional ${ }^{\circledR}$.

Procedure. All the participants took part in the research voluntarily and anonymously. They were informed about the approximate duration of the experiment and filling the forms. To conduct the research a specially equipped room with good sound insulation was allocated. Research time from 10:00 a.m. to 4:00 p.m. Performance of the four versions of the IAT took an average of 45 to 90 minutes. The participants were provided with necessary instructions and training procedures. At first they carried out IAT procedures and then filled in the questionnaires „DRS-15" and "SACS". The text of instructions was written in black letters on a white background and located in the center of the monitor screen. Each sentence began with a new line. To ensure the internal validity of the experiment the key parameters were unchanged (time of presentation of the stimulus, intervals between stimuli, the number of stimuli - words, font and chromatic parameters of the background). The participants' task was to differentiate the verbal stimuli. All target and category words were presented in lowercase letters. A stimulus word was displayed on the screen without auditory support and remained on the screen until the participant's response. The RT for each sample was recorded. The order of stimulus presentation was set by the program accidentally. Stimuli were presented in the center of the screen. Each target category related to five different target attributes. After an erroneous reaction, a red cross appeared in the center of the screen. The instruction to the participants reported that the red cross means the erroneous reaction. Each study participant took four version of the experimental IAT procedure. The order of the experimental procedures was set to each participant individually and marked in his/her card, for example, to the participant No. $1-(1,2,3,4)$, to the participant No. 2 - $(4,1,2,3)$. 
Irina Plotka, Dmitry Igonin, Jelena Shaplavska, Daiga Kruzite, Nina Blumenau. LongDistance Truck Drivers Coping Strategies and Hardiness: Self-Assessment Procedure and Implicit Association Test

\section{Results}

\section{Explicit measured variables}

Variables B (COMMITMENT), B (CONTROL), B (CHALLENGE), B (HARDINESS) were measured with DRS-15 (Bartone et. al., 2008).

Variables Assertive Actions, Avoidance, Seeking Social Support, Cautious Actions, Social Joining, Aggressive Actions, Antisocial Actions, Instinctive Actions, Indirect Actions were measured with SACS by Hobfoll (1998).

\section{Implicit measured variables}

Using the IAT, we measure variables constructed with the help of stimuli, semantically related to hardiness and its components (DRS-15). They express implicit preferences of the stimuli set forming A Category (positive effect) or B Category (negative effect) (Table 1) for each of the four IAT. They may be viewed as implicit preferences of certain properties „COMMITMENT - NONCOMMITMENT”, „CONTROL - NON-CONTROL”, „CHALLENGE - NONCHALLANGE”, „HARDINESS - NON-HARDINESS”. Quantitatively, these variables are expressed as D-scores, according to the expression (1). They are designated as D (COMMITMENT), D (CONTROL), D (CHALLENGE), D (HARDINESS).

\section{Statistical methods}

With research of descriptive statistics, extreme values of variables and compliance of data distribution with normal distribution it was found that all variables can be researched by methods of parametric statistics, using $t$-tests for means, Pearson's correlation coefficients and Multiple Regression Analysis.

To answer the first research question, the research of implicit preferences, expressed in D-scores was conducted. The D-scores is an effect size, based on each person's variance in response latencies. We viewed the division of D-scores into three intervals. If $|\mathrm{D}| \leq 0.15$ - no effect, if $\mathrm{D}<-0.15$ negative effect, if $\mathrm{D}>$ 0.15 - positive effect. Both positive and negative effects were obtained (Fig. 1, Appendix A, Fig. A1-A4).

Method: IAT

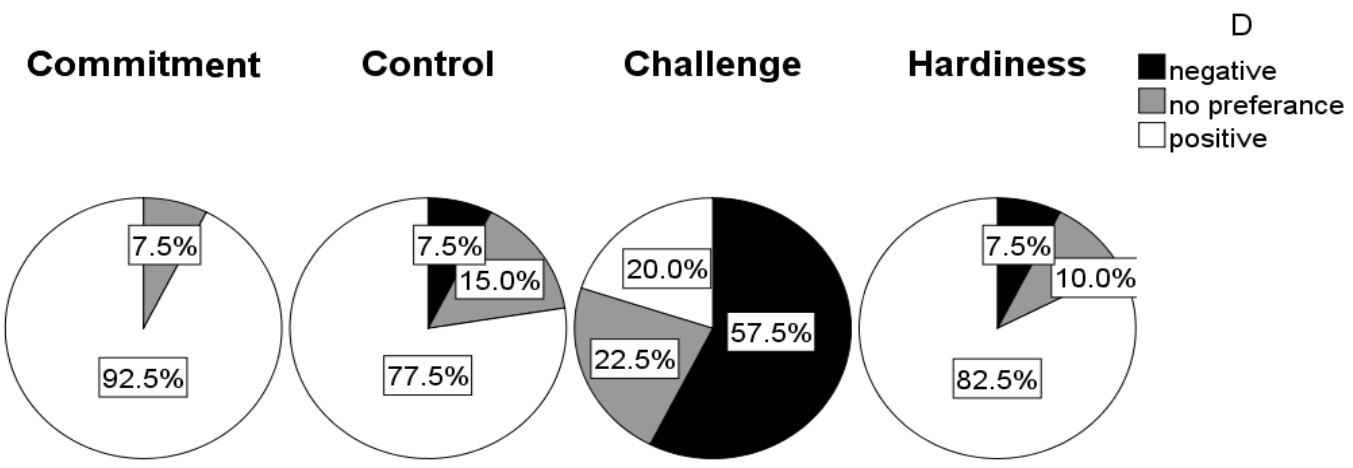

Figure 1 Percentages of sizes of the preference effect $D$ for Hardiness and its components: Challenge, Commitment, Control, measured with IAT 
With the help of Fisher's Angle Transformations Test it was found that the number of positive effects exceeds the number of negative effects for $\mathrm{D}$ (COMMITMENT): $\phi^{*}=11.57, p<.001$; for D (CONTROL): $\phi^{*}=7.15, p<.001$; and for D (HARDINESS): $\phi^{*}=7.71, p<.001$. For D (CHALLENGE) the number of negative effects exceeds the number of positive effects: $\left.\phi^{*}=3.55, p<.001\right)$.

"COMMITMENT - NON-COMMITMENT". 92.5\% of OTR truckers have the implicit preference „Commitment, Consciousness, Inclusion, Life richness, Interest.” $0.0 \%$ of OTR truckers have the implicit preference „Isolation, Detachment, Meaningless, Life monotony, Boredom."

„CONTROL - NON-CONTROL". $77.5 \%$ of OTR truckers have the implicit preference „To act, To overcome, To manage, To influence, To determine. $7.5 \%$ of OTR truckers have the implicit preference „To wait, To concede, To succumb, To go with the flow, To depend on circumstances to wait, give in, give in, go with the flow, and depend on the circumstances."

"CHALLENGE - NON-CHALLANGE". $20.0 \%$ of OTR truckers have the implicit preference „Dynamism, Changes, Risk, Uncertainty, Search.” $57.5 \%$ of OTR truckers have the implicit preference „Stability, Consistency, Trustworthiness, Safety, Stereotypeness."

"HARDINESS - NON-HARDINESS". $82.5 \%$ of OTR truckers have the implicit preference „Consciousness, Overcoming, Persistence, Energy, Risk.” 7.5 $\%$ of OTR truckers have the implicit preference „Senselessness, Lack of initiative, Passivity, Avoiding the fight, Security."

To answer the second research question the $t$-test for paired samples was used. It was found, that the mean of B (COMMITMENT) $(M=16.0, S D=2.9)$ exceeds the mean of B (CHALLENGE) $(M=12.6, S D=3.1)(t(39)=5.44, p<$ $.001)$ and the mean of B (CONTROL) $(M=16.3, S D=2.6)$ exceeds the mean of B $($ CHALLENGE) $(t(39)=6.34, p<.001)$. The differences between means of $\mathrm{B}$ (COMMITMENT) and B (CONTROL) were not revealed.

To answer the third research question the Pearson's correlation coefficients were calculated. It was found, that D (COMMITMENT) is positively related with $\mathrm{D}$ (HARDINESS): $r(40)=.42, p<.01$; $\mathrm{D}(\mathrm{CONTROL})$ is positively related with D (HARDINESS): $r(40)=.43, p<.001$.

To answer the fourth research question - to research the contribution of independent variables D (COMMITMENT), D (CONTROL), D (CHALLENGE) to the dependent variable D (HARDINESS) the multiple regression analysis was used.

Method "Backward". Method's: criteria: probability-of- $F$-to-enter $\leq .050$, probability-of- $F$-to-remove $\geq .101$. The equation for estimations: 
Irina Plotka, Dmitry Igonin, Jelena Shaplavska, Daiga Kruzite, Nina Blumenau. LongDistance Truck Drivers Coping Strategies and Hardiness: Self-Assessment Procedure and Implicit Association Test

$$
\begin{gathered}
\mathrm{D} \\
(\text { HARDINESS })(\text { estimate })= \\
=0.167+0.332 *(\text { COMMITMENT })+0.359 * \mathrm{D}(\text { CONTROL }) .
\end{gathered}
$$

The impact of each independent variable defines by "Beta-coefficients" $(\beta)$. The Beta coefficients are the coefficients in standardized regression equation.

The greatest impact on D (HARDINESS) is made by the variable $\mathrm{D}$ $\left(\right.$ CONTROL) $\left(\beta_{1}=.415, p<.01\right)$ then, by $\mathrm{D}\left(\right.$ COMMITMENT) $\left(\beta_{2}=.318, p<\right.$ $.05)$.

$R$-Square $=.337$ shows, that $33.7 \%$ of variability of the dependent variable $\mathrm{D}$ (HARDINESS) is due to the influence of the independent variables D $($ CONTROL) and D (COMMITMENT). Adjusted $R$-square $=.301$. Standard error of estimate is 0.354 . The result of ANOVA is: $F(2,37)=9.41, p<.001$.

Method "Enter". The equation for estimations:

$$
\begin{gathered}
\mathrm{D}(\text { HARDINESS })(\text { estimate })=0.130+0.360 * \mathrm{D}(\text { COMMITMENT })+ \\
+0.354 * \mathrm{D}(\text { CONTROL })-0.134 * \mathrm{D}(\text { CHALLENGE }) .
\end{gathered}
$$

The greatest impact on D (HARDINESS) is made by the variable $\mathrm{D}$ (CONTROL) $\left(\beta_{1}=.409, p<.001\right)$, then by D (COMMITMENT) $\left(\beta_{2}=-.345, p<\right.$ $.05)$, then, by $\mathrm{D}$ (CHALLENGE) $\left(\beta_{3}=-.134, p=.332, \mathrm{~ns}\right) . R$-Square $=.355$ shows, that $35.5 \%$ of variability of the dependent variable is due to the influence of the independent variables D (S), D (COMMITMENT), D (CONTROL) and D (CHALLENGE). Adjusted $R$-square $=.301$. Standard error of estimate 0.354 . The result of ANOVA is: $F(3,36)=6.59 ; p=.001$.

To answer the fifth research question the Pearson's correlation coefficients were calculated. It was found, that B (CHALLENGE) is positively related with B (HARDINESS): $r(40)=.678, p<.001 ; \mathrm{B}(\mathrm{CONTROL})$ is positively related with $\mathrm{B}$ (HARDINESS): $r(40)=.700, p<.001 ; \mathrm{B}(\mathrm{COMMITMENT})$ is positively related with B (HARDINESS): $r(40)=.730, p<.001$.

To answer the sixth research question all the correlation coefficients between explicit and implicit measured hardiness and its components are statistically insignificant. Also the authors held Factor Analysis with two factors (Kaiser criterion), extraction method: Principal Component Analysis. Rotation's method Varimax with Kaiser Normalization, Kaiser-Meyer-Olkin measure of sampling adequacy equals to .54 (miserable), Bartlett's test of Sphericity $\chi^{2}(21)=$ $32.63, p \leq .05$, cumulative percent of total variance explained $48.7 \%$. As a result, it was found that Component 2 only describes explicit variables B (COMMITMENT), B (CONTROL), B (CHALLENGE) and the Component 1 describes only implicit variables D (COMMITMENT), D(CONTROL), D 
(HARDINESS) without D (CHALLENGE) (Fig. 3). These components can be called the "Explicit hardiness factor" and "Implicit hardiness factor".

The results of implicit and explicit measurements of hardiness and its components are independent from each other.

Answering the seventh research question Pearson and Spearman correlations coefficients were calculated (Appendix A, Table A1). Found statistically significant relationships are shown in Fig. 2.

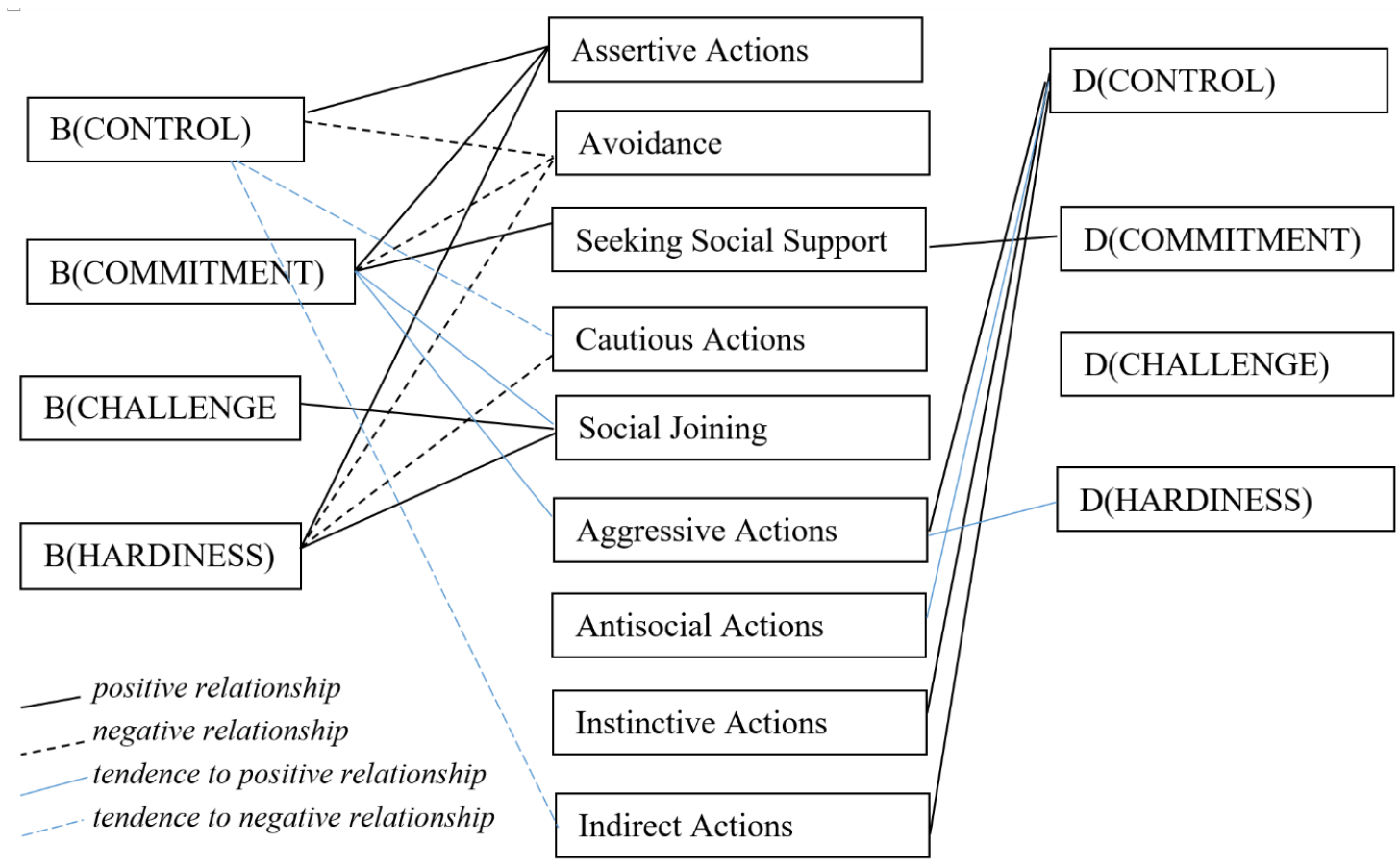

Fig.2 The relationship between coping strategies and hardiness and its components, measured using the IAT and DRS-15 (Bartone)

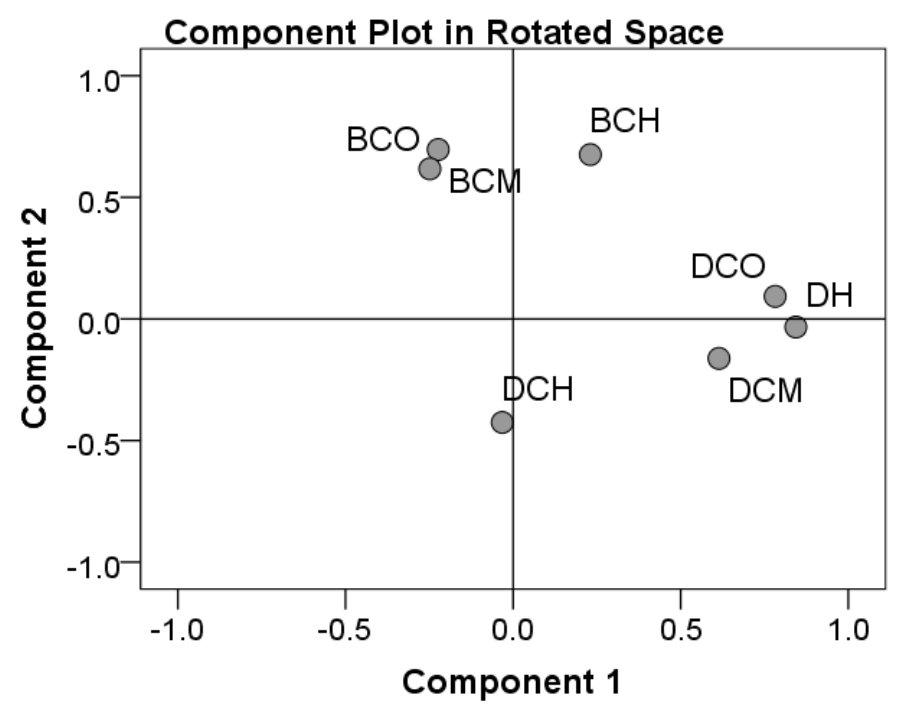

Figure 3 Component Plot in Rotated Space. Notations: B (COMMITMENT) - BCM, B (CONTROL) - BCO, B (CHALLENGE) - BCH, D (COMMITMENT -DCM, D (CONTROL) - DCO, D (CHALLENGE) - DCH, D (HARTINESS) -DH 
Irina Plotka, Dmitry Igonin, Jelena Shaplavska, Daiga Kruzite, Nina Blumenau. LongDistance Truck Drivers Coping Strategies and Hardiness: Self-Assessment Procedure and Implicit Association Test

\section{Discussion and conclusions}

As a result of the research its aim was implemented and the main results are presented.

1. For the sample of long-distance truck drivers we used the four experimental procedures of the Implicit Association Test developed by the authors, designed with the help of stimuli, semantically related to hardiness and its components. These IAT allow to measure variables that can be considered as implicit preferences: „COMMITMENT - NON-COMMITMENT” (,commitment, consciousness, inclusion, interest, life richness” - ,isolation, detachment, meaningless life monotony, boredom”; "CONTROL - NONCONTROL" (,to act, to overcome, to manage, to influence, to determine" - ,to wait, to concede, to succumb, to go with the flow, to depend on circumstances"); "CHALLENGE - NON-CHALLANGE” (,dynamism, changes, risk, uncertainty and search" - „stability, consistency, trustworthiness, safety, stereotypeness"); „HARDINESS - NON-HARDINESS” (,consciousness, overcoming, persistence, energy, risk" - „senselessness, lack of initiative, passivity, avoiding the fight, security"). Quantitatively, these variables are expressed in terms of D-scores IAT.

2. Long-distance truck drivers have implicit preferences: "COMMITMENT" (,commitment, consciousness, inclusion, interest, life richness") vs "NONCOMMITMENT" (,isolation, detachment, meaningless life monotony, boredom"); "CONTROL" (,to act, to overcome, to manage, to influence, to determine") vs "NON-CONTROL" (,to wait, to concede, to succumb, to go with the flow, to depend on circumstances"); "HARDINESS" (,,consciousness, overcoming, persistence, energy, risk") vs "NON-HARDINESS" (,senselessness, lack of initiative, passivity, avoiding the fight, security") and negative implicit preference "NON-CHALLENGE" (,stability, consistency, trustworthiness, safety, stereotypeness”) vs “CHALLENGE” (,dynamism, changes, risk, uncertainty, search").

The negative preference "NON-CHALLENGE" was observed on a sample of the guards (Plotka et. al., 2015). On a sample of militaries (Shaplavska \& Plotka, 2014) the negative preference „NON-COMMITMENT” was observed. On a sample of football players the negative implicit preference „NONCONTROL" (Plotka et. al., 2013) was observed.

3. The research shows that the hardiness component "CHALLENGE” is specifically manifested in long-distance truck drivers. Explicitly measured "CHALLENGE" component correlates only with the explicit measured overall "HARDINESS", but does not correlate with explicitly measured hardiness components "CONTROL" and "COMMITMENT". With this "CONTROL" and "COMMITMENT" positively correlate with each other. Both explicitly measured "CHALLENGE", and implicitly measured by the IAT variable expressing 
implicit preferences "CHALLENGE-NON-CHALLENGE" correlate (positively) only with "Social Joining" (among all coping strategies). According to Maddi (2013), ,challenge" defines openness and receptivity of a person to the changes taking place in his/her life, which are considered as new opportunities (as opposed to fear of change). If a person is able to perceive life situations as a challenge, he/she achieves a sense of satisfaction, using stress as an opportunity for development. Such people believe that you can learn both on errors, and the achievements. Obviously, long-distance truck drivers, by virtue of their profession, should treat changes with extreme caution, to rely more on the adherence to their professional normativity, adherence to regulations, laws and rules. Implicit preferences „stability, consistency, trustworthiness, safety, stereotypeness" and „dynamism, changes, risk, uncertainty and search” in longdistance truck drivers witness to this. It is obvious that in stressful situations the best correlate to "CHALLENGE" is to join in a social contact.

4. An interesting fact was that the variable of implicit preferences CONTROL-NON-CONTROL (,to act, to overcome, to manage, to influence, to determine" - „to wait, to concede, to succumb, to go with the flow, to depend on circumstances") obtained using the IAT is positively associated with destructive coping strategies to cope with stress (,Aggressive Actions”, „Instinctive Actions", "Indirect Actions") and tends to have positive relationship with „Antisocial Actions."

The implicit preference ,to act, to overcome, to manage, to influence, to determine" in long-distance truck drivers corresponds to the choice of behavioral strategies in stress situations associated with a critical attitude towards people around, and also with immediate ,storm" of problems, and focus on gaining control over the situation (aggressive actions), actions without adequate conscious control, under the influence of external circumstances or because of emotional distress (instinctive actions), manipulatively, hiding one's true intentions (indirect actions). These implicit preferences tend to correspond to actions taken to harm someone, or expressed in indifference, obtaining benefits through the use of „weak points" of other people in order to take a better position (aggressive driving, overtaking).

Implicit preference ,, To wait, To concede, To succumb, To go with the flow, To depend on circumstances" in long-distance truck drivers corresponds to choosing the behavioral strategies in stressful situations related to the uncritical attitude towards the environment, passive attitude to the problems, indifference to gaining control over the situation and deliberately controlled actions in the situation (the low score on the scale of ,Aggressive Actions"), actions, not taking into account the influence of external circumstances, or, as opposed to emotional experiences (the low score on the scale of ,Instinctive Actions”), not hiding one's true intentions (the low score on the scale of „Indirect Actions"). These implicit 
preferences in long-distance truck drivers tend to conform to acts committed without intent to harm someone, indifference to obtain benefits through the use of „weak points" of others, indifference to taking a better position (the low score on the scale of „Antisocial Activities").

5. Explicitly measured commitment B (COMMITMENT) positively associated with "Assertive Actions" and "Seeking Social Support". It is negatively associated with "Avoidance". It has a tendency to positive relationship with "Social Joining" and "Aggressive Actions".

High scores on the "Commitment" scale point the motivation to selfrealization, leadership, healthy way of thinking and ability to be included in the solution of vital problems, despite the presence of stressful situations (Maddi, 2013).

High scores on the "COMMITMENT" scale corresponds to the high score on the scales of „Assertive Actions" (person's ability to be independent from external influences and evaluations of people around, assurance of one's activities, honesty, integrity, self-respect and respect for others) and „Seeking Social Support" (attempts to rely on the others in an effort to get emotional and tangible support, advice) and the low scores on the „Avoidance" scale (mental striving and behavioral efforts to solve the challenges, to achieve success).

High scores on the "COMMITMENT" scale tend to meet high scores in social joining (actions in concert with the group) and the high scores on the "Aggressive Actions" scale (critical relation to the environment, they imply the immediate "storm" of the problems and are aimed at gaining control over the situation rather than causing harm).

6. Explicitly measured "CONTROL" is positively related to assertive actions. It is negatively associated with "Avoidance". It has a tendency to negative correlation with "Cautious Actions" and "Indirect Actions".

High scores on the „CONTROL" scale point the ability to control the actions and events of what is happening, to search for active ways to influence upon stressful effects, person's motivation to turn all the stress from potential disasters into opportunities for personal growth. It is the desire for action, for fight that allows you to influence the outcome of events, despite the fact that this influence may not be absolute, and success is not guaranteed (Maddi, 2013).

High scores on the „CONTROL” scale corresponds to the high score on the scales of „Assertive Action” (person's ability to be independent from external influences and evaluations of people around, assurance of one's activities, honesty, integrity, self-respect and respect for others) and the low scores on the „Avoidance" scale (mental striving and behavioral efforts to solve the challenges, to achieve success).

High scores on the "CONTROL" scale corresponds to the low score on the scale of „Cautious Actions” (as a sign of power and as a lack of the need to avoid 
being tactless; unwillingness to understand the others and unwillingness to act in such a way that the interacting group would provide supported and would not move away) and low scores on the scale of „Indirect Action" (not to hide one's true intentions, not to manipulate).

7. Explicitly measured "CHALLENGE" is positively related to "Social Joining".

High scores on the "CHALLENGE" scale characterize the person's openness and receptivity to changes taking place in his/her life, which are considered as new opportunities (as opposed to fear of change). If a person is able to perceive life situations as a challenge, he/she achieves a sense of satisfaction, using stress as an opportunity for development. Such people believe that you can learn both on errors, and on the achievements (Maddi, 2013).

High scores on the "CHALLENGE” scale (openness and receptivity to changes, which are seen as opportunities) correspond to the high score on the scale of ,Social Joining" (action in concert with the group).

8. Explicitly measured "HARDINESS" is positively related to "Assertive Actions" and "Social Joining". It is negatively related to "Avoidance" and "Cautious Actions".

High scores on the „HARDINESS" scale correspond to the high score on the scale of „Assertive Actions" (person's ability to be independent from external influences and evaluations of people around, assurance of one's activities, honesty, integrity, self-respect and respect for others) the high score on the scale of „Social Joining” (action in concert with the group).

Low scores on the „HARDINESS" scale correspond to the low score on the „Avoidance" scale (mental striving and behavioral efforts to solve the challenges, to achieve success) and the low scores on the scale of "Cautious Actions" (as a sign of power and as a lack of the need to avoid being tactless; unwillingness to understand the others and indifference to the support of the interacting group).

9. "COMMITMENT", estimated using the IAT, is positively related to „Seeking Social Support," as well as "COMMITMENT”, measured using DRS15 (Bartone). High scores of "COMMITMENT", estimated using the IAT, point the implicit preference of ,commitment, consciousness, inclusion, interest and life richness." They correspond in long-distance truck drivers the high score on the scale of "Seeking Social Support” (attempts to rely on the others in an effort to get emotional and tangible support, advice). Low scores of "COMMITMENT", estimated using the IAT, point the implicit preference ,isolation, detachment, meaningless life monotony, boredom".

10. The monotonic relationship between explicitly measured variables of hardiness and its components and the corresponding implicit variables was not revealed. The application of factor analysis to explicitly and implicitly measured components of hardiness has revealed two factors, one of which is described only 
Irina Plotka, Dmitry Igonin, Jelena Shaplavska, Daiga Kruzite, Nina Blumenau. LongDistance Truck Drivers Coping Strategies and Hardiness: Self-Assessment Procedure and Implicit Association Test

with the explicit components of hardiness - commitment, control and challenge), and the other factor is described only with implicitly estimated variables „CONTROL - NON-CONTROL”, „COMMITMENT - NON-COMMITMENT”. These factors can be called the „Explicit hardiness factor” and „Implicit hardiness factor".

11. Limitation of the research is that the research was conducted only on the sample not large enough that do not make it possible to study non-monotonic relationships and the effects of matching the results of implicit and explicit measurements associated with non-monotonicity.

12. The prospects for further research can be to attract participants of different age groups.

\section{References}

Amirfakhraei, A., Taghinejad, N., \& Sadeghifar, E. ( 2013). Relationship between risky driving behavior and sensation - Seeking and sex among students of Islamic Azad University Bandar Abbas, Iran, in 2012. Journal of Basic and Applied Scientific Research, 3 (3), 293-301.

Bartone, P.T., Eid, J., Hystad, S. W., Johnsen, B. H., \& Laberg, J. C. (2008). Norwegian adaptation of the DRS - Dispositional Resilience Scale for measuring hardiness under stress. Presented at the American Psychological Association Convention. Boston: MA.

Bartone, P. T. (2006). Resilience under military operational stress: Can leaders influence hardiness? Military Psychology, 18, 131-148.

Bartone, P. T., Kelly D. R., \& Matthews, M. D. (2013). Psychological hardiness predicts adaptability in military leaders: A prospective study. International Journal of Selection and Assessment, 21, 200-210.

Bartone, P. T., Roland, R. R., Picano, J. J., \& Williams, T. J. (2008). Psychological hardiness predicts success in US Army Special Forces candidates. International Journal of Selection and Assessment, 16 (1), 78-81.

Benfield, J. A., Szlemko, W. J., \& Bell, P. A. (2007). Driver personality and anthropomorphic attributions of vehicle personality relate to reported aggressive driving tendencies. Personality and Inidvidual Differences, $42 \quad$ (2), 247-258. DOI:10.1016/j.paid.2006.06.016

Bonanno, G. A. (2004). Loss, trauma, and human resilience: Have we underestimated the human capacity to thrive after extremely aversive events. American Psychologist, 59 (1), 20-28.

Britt, T. W., Adler, A. B., \& Bartone, P. T. (2001). Deriving benefits from stressful events: The role of engagement in meaningful work and hardiness. Journal of Occupational Health Psychology, 6, 53-63.

Clarke, S., \& Robertson, I. T. (2005). A meta-analytic review of the big five personality factors and accident involvement in occupational and non-occupational settings. Journal of Occupational and Organizational Psychology, 78, 355-376.

Contrada, R. J. (1989). Type A behavior, personality hardiness, and cardiovascular responses to stress. Journal of Personality and Social Psychology, 57, 895-903. 
Dahlen, E. R., Martin, R. C., Ragan, K., \& Kuhlman, M. M. (2005). Driving anger, sensation seeking, impulsiveness, and boredom proneness in the prediction of unsafe driving. Accident Analysis \& Prevention, 37 (2), 341-348.

Delahaija, R., Gaillard, A. W. K., \& van Damb, K. (2010). Hardiness and the response to stressful situations: Investigating mediating processes. Personality and Individual Differences, 5, 386-390.

Fernandes, R. F., Hatfield, J., \& Job, R. F. S. (2006). Examination of different predictors of different risky driving behaviours in young NSW drivers. Final report for the Motor Accidents Authority of NSW, Australia. Retrieved from http://www. irmrc.unsw.edu.au/documents/ predictors\%20of\%20risky\% 20drving\%20report.pdf.

Greenwald, A. G., McGhee, D. E., \& Schwartz, J. L. K. (1998). Measuring individual differences in implicit cognition: The Implicit Association Test. Journal of Personality and Social Psychology, 74, 1464-1480.

Grote, G., Weichbrodt, J. C., Günter, H., Zala-Mezö, E., \& Künzle, B. (2009). Coordination in high-risk organizations: the need for flexible routines. Cognition, Technology \& Work, 11, 17-27.

Hobfoll, S. E. (1998). Stress, culture, and community. The psychology and philosophy of stress. New York \& London: Plenum Press.

Hubicka, B., Killmen, H., Hiltunen, A., \& Bergman, H. (2010). Personality traits and mental health of severe drunk drivers in Sweden. Social Psychiatry and Psychiatric Epidemiology, 45 (7), 723-731.

Jovanovic, D., Lipovac, K., Stanojevic, P., \& Stanojevic, D. (2011). The effects of personality traits on driving-related anger and aggressive behaviour in traffic among Serbian drivers. Transportation Research, Part F: Traffic Psychology and Behaviour, 14 (1), 43-53. doi: 10.1016/j.trf.2010.09.005.

Kelly, D. R., Matthews, M. D., \& Bartone, P. T. (2005). Hardiness predicts adaptation to a challenging military environment. Paper presented at the International Applied Military Psychology Symposium. Washington DC.

Kobasa, S. C., Maddi, S. R., \& Kahn, S. (1982). Hardiness and health: A prospective study. Journal of Personality and Social Psychology, 42, 168-177.

Lajunen, T. (2001). Personality and accident liability: Are extraversion, neuroticism and psychoticism related to traffic and occupational fatalities? Personality and Individual Differences, 31 (8), 1365-1373.

Maddi, S. R. (2005). On hardiness and other pathways to resilience. American Psychologist, 60 (3), 261-262.

Maddi, S. R. (2013). Hardiness turning stressful circumstances into resilient growth. Springer Briefs in Psychology, XI, 88 p.

Oltedal, S., \& Rundmo, T. (2006). The effects of personality and gender on risky dirving behaviour and accident involvement. Safety Science, 44 (7), 621-628.

Petty, R. E., Fazio, R. H., \& Brinol, P. (2009). Attitudes: Insights from the New Implicit Measures. New York: Psychology Press.

Plotka, I., Shaplavska, J., Blumenau, N., \& Gajevska, T. (2015). Research in hardiness of security guards with Implicit Association Test and self-evaluation procedures. In L. Malinovska (Ed), Proceedings of 14-th International Scientific Conference Engineering for Rural Development Jelgava, Latvia, 20-22.05.2015 V.14 (pp. 735-741). Jelgava: Latvia University of Agriculture Faculty of Engineering. ISSN 1691-5976. ABSTRACTED AND INDEXED: Elsevier SCOPUS, Thomson Reuters Web of Science, 
Irina Plotka, Dmitry Igonin, Jelena Shaplavska, Daiga Kruzite, Nina Blumenau. Long-

Distance Truck Drivers Coping Strategies and Hardiness: Self-Assessment Procedure and

Implicit Association Test

AGRIS, CAB ABSTRACTS, CABI full text, EBSCO Academic Search Complete http://tf.llu.lv/conference/proceedings2015/

Plotka, I., Shaplavska, J., Blumenau, N., Igonin, D., \& Kunavin, J. (2013, October). The study of hardines with Implicit - Association Test and self-assessment procedure in risky professions. In Abstract Book of the International Scientific and Practice Conference "Business. Society. Human" 30-31 October, 2013, National Research University Higher School of Economics, Russia, Moscow (pp. 291-293). Moscow: Higher School of Economics. http://bsh.hse.ru/abstract_book_2013

Renner, W., \& Anderle, F. G. (2000). Venturesomeness and extraversion as correlates of juvenile drivers' traffic violations. Accident Analysis \& Prevention, 32 (5), 673-678.

Rudman, L. A. (2011). Implicit measures for social and personality psychology. London: Sage.

Sandvik, A. M., Bartone, P. T., Hystad, S. W., Phillips, T. M., Thayer, J. F., \& Johnsen, B. H. (2013). Psychological hardiness predicts neuroimmunological responses to stress. Psychology, Health \& Medicine, 1-9

Schlosberg, H. (1952). The description of facial expressions in terms of two dimensions. Journal of Experimental Psychology, 44, 229-237.

Scott-Parker, B., Watson, B., King, M. J., \& Hyde, M. K. (2012). A comprehensive investigation of the risky driving behaviour of young novice drivers. In Directions in Road Safety Research Forum, 18-19 June 2012. Queensland University of Technology, Brisbane, OLD. Retrieved from https://eprints.qut.edu.au./59638/1/Bridie_Scott_Parker_Thesis.pdf.

Scott-Parker, B., Watson, B., King, M. J., \& Hyde, M. K. (2013). A further exploration of sensation seeking propensity, reward sensitivity, depression, anxiety, and the risky behaviour of young novice drivers in a structural equation model. Accident Analysis \& Prevention, 50, 465-471.

Silberman, K. (2014). Media influence on risky driving behaviours among adolescents and emerging adults. A thesis submitted in partial fulfilment of the requirements for the Honours in the Major Program in Psychology in the College of Sciences and in The Burnett Honours College at the University of Central Florida. Orlando, Florida. Retrieved from http://etd.fcla.edu/CF/CFH0004680/Silberman_Kelly_A_201412_BS.pdf

Shaplavska, J., \& Plotka, I. (2011). Research vitality components, tolerance uncertainty and stress situation management strategy of rescue officers. Professional studies: theory and practice, $8,270-275$.

Shaplavska, J., \& Plotka, I. (2012). Study of Connection of Hardiness and Social Psychological Adaptation of Students. Journal of Teaching and Education, 1 (6). 247-253.

Shaplavska, J., \& Plotka, I. (2014). Research of hardiness using explicit and implicit measures (on the basis of professions related to risk). International Business: Innovations, Psychology, Economics, 5 (1), 27-41.

Stephens, V. (2011). Self-reported risky driver behaviour and the Big Five personality traits. In Manchester Metropolitan University Journal, May 2011. UK: University of Worcester. Retrieved from https://e-space.mmu.ac.uk/576743/

Sumer, N. (2003). Personality and behavioral predictors of traffic accidents: testing a contextual mediated model. Accident analysis and Prevention, 35 (6), 949-964.

Taubman - Ben-Ari, O., \& Yehiel, D. (2012). Driving styles and their associations with personality and motivation. Accident Analysis and Prevention, 45, 416-422. 
Ucho, A., Terwase, J. M., \& Ucho, A. A. (2016). Influence of Big Five personality traits and locus of control on road safety rules compliance among motorcycle riders in NorthCentral Nigeria. Asia Pacific Journal of Education, Arts and Sciences, 3 (1), 1-9.

Ulleberg, P., \& Rundmo, T. (2002). Risk-taking attitudes among young drivers: the psychometric qualities and dimensionality of an instrument to measure young drivers' risktaking attitudes. Scandinavian Journal of Psychology, 43, 197-209.

Ulleberg, P., \& Rundmo, T. (2003). Personality, attitudes and risk perception as predictors of risky driving behaviour among young drivers. Safety Science, 41 (5), 427-443.

Wiebe, D. J. (1991). Hardiness and stress moderation: A test of proposed mechanisms. Journal of Personality and Social Psychology, 60, 89 - 99.

Yagil, D. (2001). Reasoned action and irrational motives: A prediction of drivers' intention to violate traffic laws. Journal of Applied Social Psychology, 31, 720-740. 
Irina Plotka, Dmitry Igonin, Jelena Shaplavska, Daiga Kruzite, Nina Blumenau. LongDistance Truck Drivers Coping Strategies and Hardiness: Self-Assessment Procedure and Implicit Association Test

Appendix A

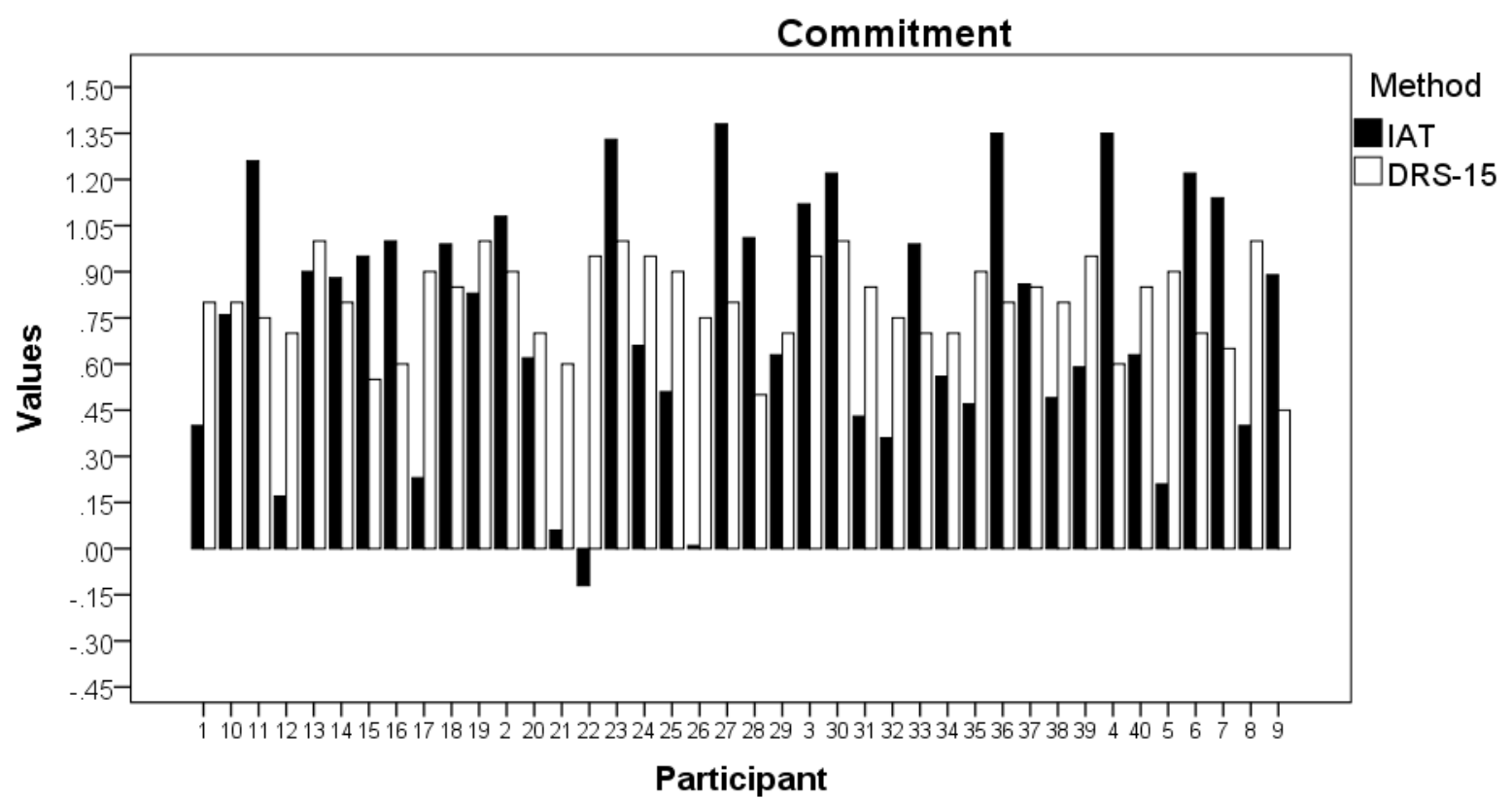

Figure A1 Values of the variable Commitment, measured using the experimental procedure of IAT (black bars) and the P. Bartone technique (DRS-15), divided by 20 (gray bars)

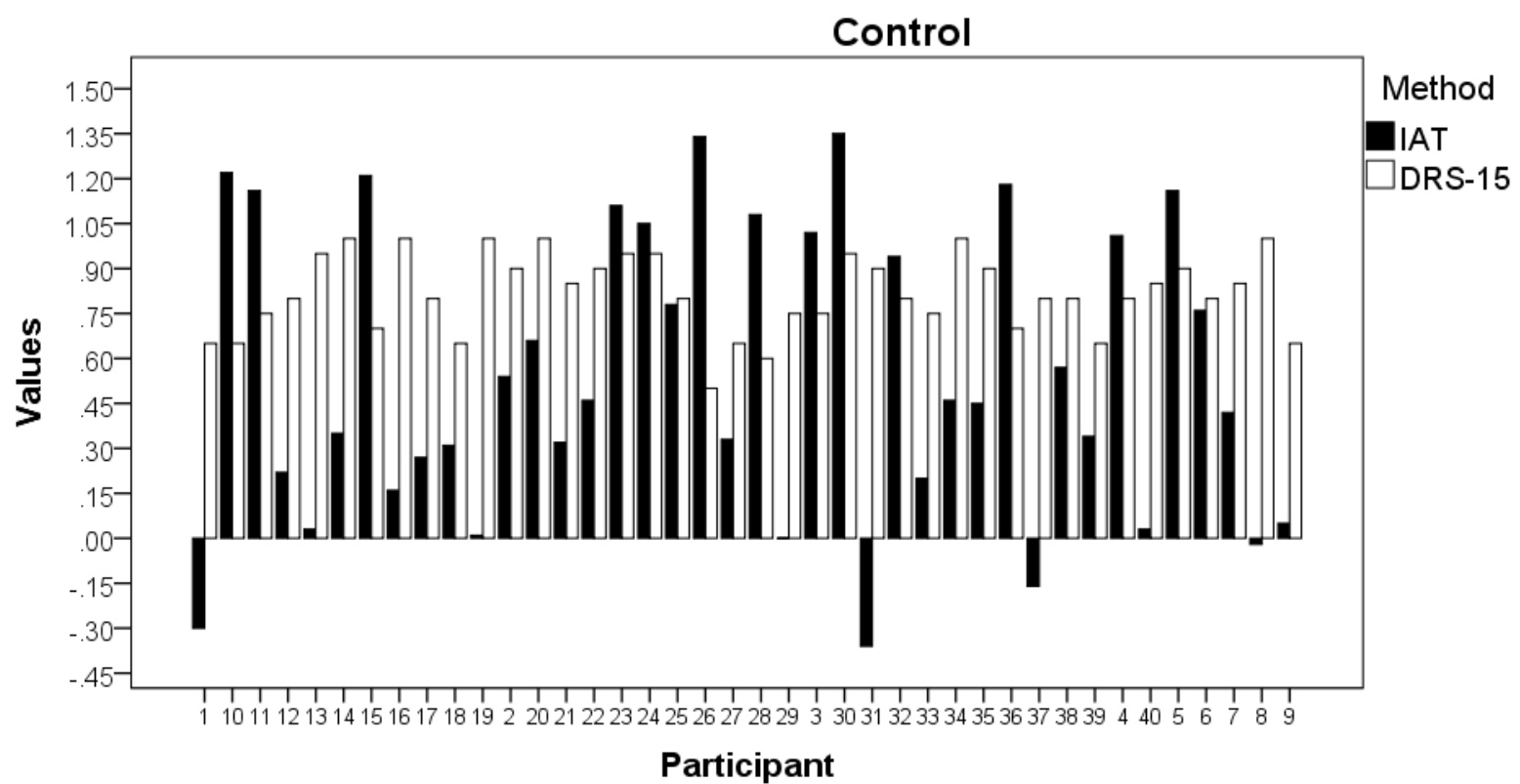

Figure A2 Values of the variable Control, measured using the experimental procedure of IAT (black bars) and the P. Bartone technique (DRS-15), divided by 20 (gray bars) 


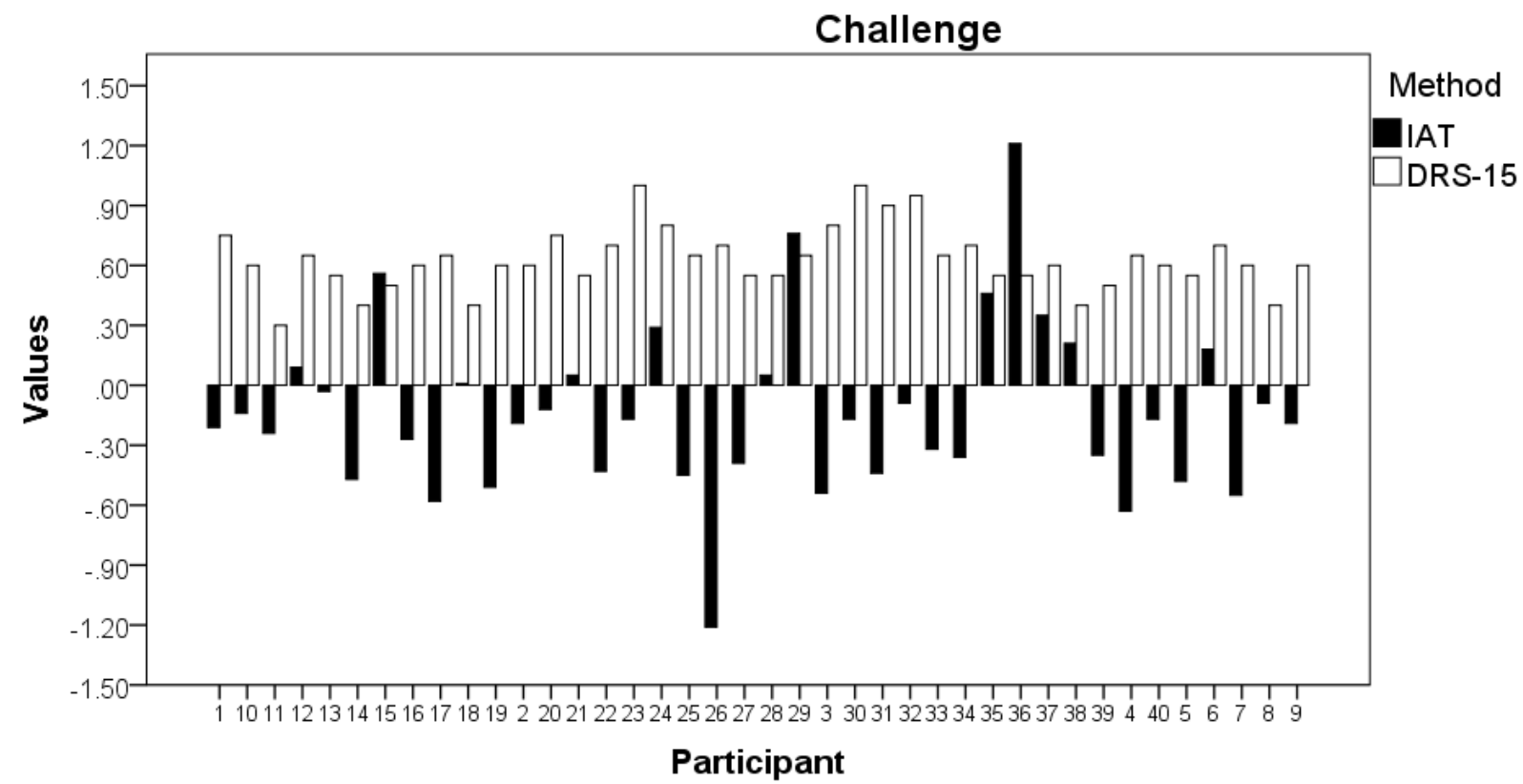

Figure A3 Values of the variable Challenge, measured using the experimental procedure of IAT (black bars) and the P. Bartone technique (DRS-15), divided by 20 (gray bars)

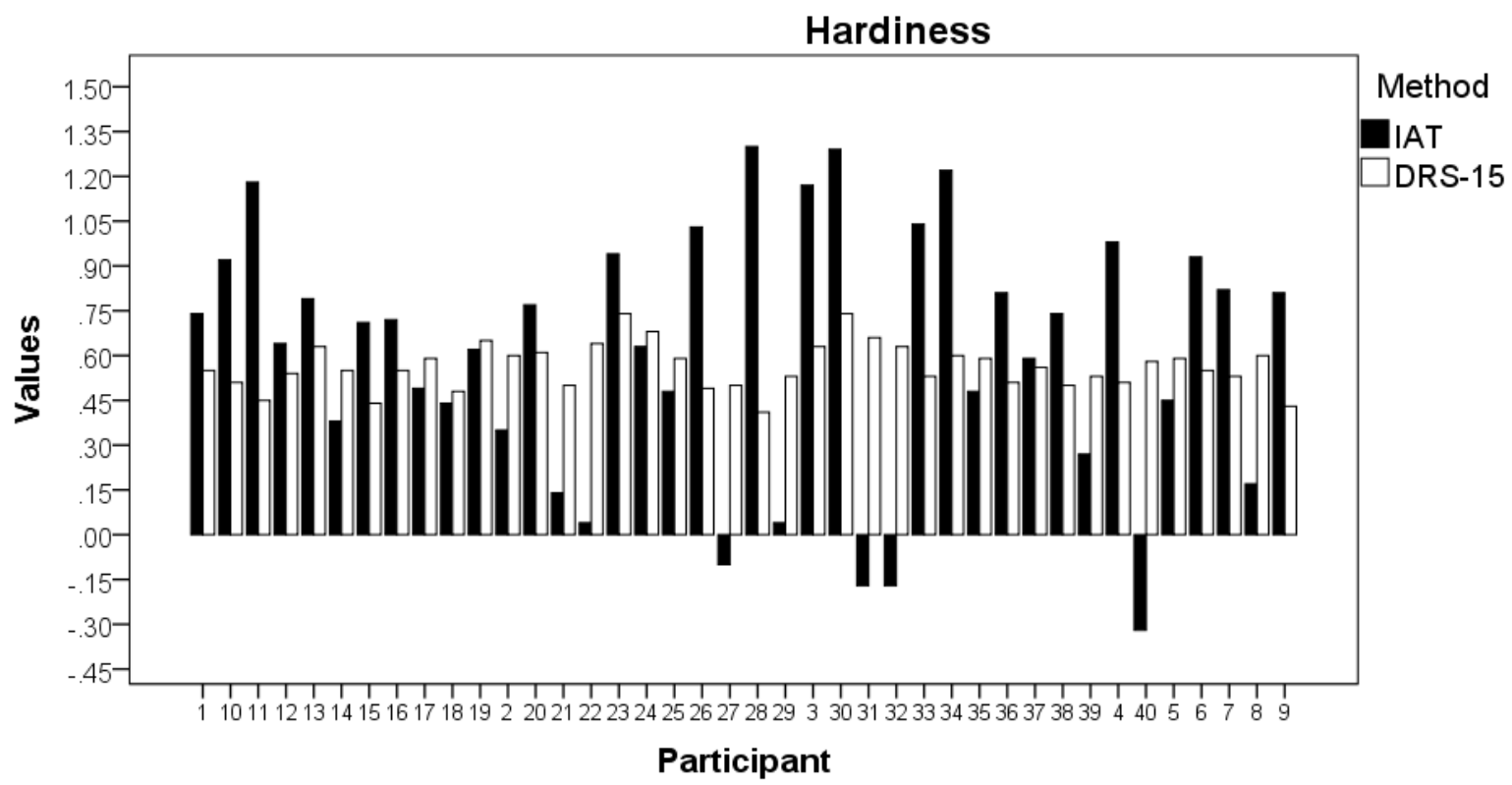

Figure F4 Values of the variable Commitment, measured using the experimental procedure of IAT (black bars) and P. Bartone technique (DRS-15), divided by 80 (gray bars) 
Irina Plotka, Dmitry Igonin, Jelena Shaplavska, Daiga Kruzite, Nina Blumenau. LongDistance Truck Drivers Coping Strategies and Hardiness: Self-Assessment Procedure and Implicit Association Test

Table A1 Statistically significant correlation coefficients (Pearson $r$, Spearman, $r$ s) and $p$-values

\begin{tabular}{|c|c|c|}
\hline Variable 1 & Variable 2 & $\begin{array}{l}\text { Correlation Coefficients } \\
\text { Pearson } r \text {, Spearman, } r \text { s } \\
\text { and } p \text {-values }\end{array}$ \\
\hline B(COMMITMENT) & Assertive action & $r(40)=.37^{*}, p=.017<.05$ \\
\hline B(COMMITMENT) & Avoidance & $r(40)=-.35^{*}, p=.025<.05$ \\
\hline B(COMMITMENT) & Seeking social support & $r(40)=.33^{*}, p=.037<.05$ \\
\hline B(COMMITMENT) & Social joining & $r_{\mathrm{S}}(40)=.26^{*}, p=.101$ \\
\hline B(COMMITMENT) & Aggressive action & $r_{\mathrm{S}}(40)=.27^{*}, p=.094<.1$ \\
\hline B(CONTROL) & Assertive action & $r(40)=.33^{*}, p=.037<.05^{*}$ \\
\hline B(CONTROL) & Avoidance & $r(40)=-.34^{*}, p=.035<.05$ \\
\hline B(CONTROL) & Cautious action & $r(40)=.26, p=.108$ \\
\hline $\mathrm{B}(\mathrm{CONTROL})$ & Indirect action & $r(40)=-.26, p=.106$ \\
\hline B(CHALLENGE) & Social joining & $r(40)=.36^{*}, p=.025<.05$ \\
\hline B(HARDINESS) & Assertive action & $r(40)=.33^{*}, p=.040<.05$ \\
\hline B(HARDINESS) & Avoidance & $r(40)=-.42 * *, p=.007<.01$ \\
\hline B(HARDINESS) & Cautious action & $r_{\mathrm{s}}(40)=-.32 *, p=.046<.05$ \\
\hline B(HARDINESS) & Social joining & $r_{\mathrm{S}}(40)=.35^{*}, p=.026<.05$ \\
\hline D(COMMITMENT) & Seeking social support & $r(40)=.33^{*}, p=.040<.05$ \\
\hline $\mathrm{D}(\mathrm{CONTROL})$ & Instinctive action & $r(40)=.42 * *, p=.007<.01$ \\
\hline $\mathrm{D}(\mathrm{CONTROL})$ & Aggressive action & $r(40)=.33^{*}, p=.041<.05$ \\
\hline D(CONTROL) & Antisocial action & $r_{\mathrm{S}}(40)=.30, p=.062<.1$ \\
\hline $\mathrm{D}(\mathrm{CONTROL})$ & Indirect action & $r(40)=.36^{*}, p=.023<.05$ \\
\hline D(HARDINESS) & Aggressive action & $r_{\mathrm{S}}(40)=.26, p=.109$ \\
\hline Age & $\mathrm{B}(\mathrm{CONTROL})$ & $r(40)=-.33^{*}, p=.037<.05$ \\
\hline Age & B(CHALLENGE) & $r(40)=-.34^{*}, p=.030<.05$ \\
\hline Age & B(HARDINESS) & $r(40)=-.44^{* *}, p=.004<.01$ \\
\hline Age & Avoidance & $r(40)=.41^{* *}, p=.010<.01$ \\
\hline Work experience & D(CHALLENGE) & $r_{\mathrm{S}}(40)=-.30, p=.064<.1$ \\
\hline Work experience & Indirect action & $r_{\mathrm{S}}(40)=.32, p=.044<.05$ \\
\hline
\end{tabular}

